\title{
Systems
}

Volume 22, Issue 4, pp. 231-243, 2021

DOI: https://doi.org/10.48009/4_iis_2021_249-262

\section{Equity and satisfaction in IT: A current analysis}

\author{
Alan Peslak, Penn State University, arp14@psu.edu \\ Wendy Ceccucci, Quinnipiac University,ceccucci@qu.edu \\ Scott Hunsinger, Appalachian State University, hunsingerds@appstate.edu \\ Patricia Sendall, Merrimack College, sendallp@merrimack.edu
}

\begin{abstract}
Information technology is generally seen as a gender-biased, male dominated profession. In addition, there have been studies that suggest that other inequities may exist including both race and ethnicity, sexual preference, and age. Our study reviews the 2020 StackOverflow annual survey to determine if there are significant differences in key measurement factors such as salary based on age, gender, ethnicity, and sexual preference. Our study found no significant differences in salary based on age or sexual preference. We did find large and significant salary differences based on race/ethnicity and gender. Also, we found steadily increasing salary with age, with no major older age inequity. In addition, we analyzed job satisfaction. In this analysis, we found a large a significant difference in ethnicity here as well.
\end{abstract}

Keywords: Equity, Gender, Ethnicity, Age, Discrimination, Sexuality

\section{Introduction}

This paper looks at two variables, compensation and job satisfaction, based on age, gender, ethnicity, and sexual preference. The use of these two variables as a measure of equity and discrimination is well supported in the literature. Jordan, Clark and Waldren (2007) extensively studied gender inequity and used two measures: gender pay gap and promotional glass ceiling. They used compensation as a proxy for reviewing inherent gender inequity. Similarly, Pook, Fustos, and Marian (2003) used job satisfaction as a proxy dependent variable to study gender inequity.

In the U.S. there are several laws in place to attempt to prevent the bias or inequality of compensation for reasons of gender, age, ethnicity, and sexual preferences. The Equal Pay Act requires that men and women in the same workplace be given equal pay for equal work. The jobs need not be identical, but they must be substantially equal. Similarly, workers who are 40 or older are protected against pay discrimination under the federal Age Discrimination in Employment Act. The federal Equal Employment Opportunity Act prevents an employer from refusing to hire or to impose conditions based upon race, ethnicity, or national origin. In June 2020, in the Bostock v. Clayton County case (Bostock 2020) the Supreme Court of the United States ruled that Title VII of the Civil Rights Act of 1964 prohibits discrimination based on sexual orientation or transgender status. This paper looks at compensation based on these factors.

Organizational behaviorists and organizational psychologists have long studied the subject of employees' job satisfaction. The literature includes several facets of what variables make up job satisfaction. According to Lumley, Coetzee, Tladinyane \& Ferreira (2011), job satisfaction can be defined as "an individual's total feeling about their job and the attitudes they have towards various aspects or facets of their job, as well as an attitude and perception that could consequently influence the degree of fit between the individual and the organization" (pg. 101). Employee satisfaction is "determined by subjective perceptions related to the 


\section{Issues in Information Systems}

Volume 22, Issue 4, pp. 249-262, 2021

treatment received by the organization, for instance, policies of rewards, hiring and firing policies, performance and retribution." (Crespi-Vallbona \& Mascarilla-Miro, 2018, pg. 36). Sempane, Rieger \& Roodt (2002), assert that job satisfaction is made up of many variables such as "structure, size, pay, working conditions and leadership", all representatives of organizational climate (pg. 23). Some of these variables may also include the "importance of job position, teamwork atmosphere, leadership, recognition and compensation, physical labor conditions and personal labor conditions as key aspects of employees' wellbeing." (Crespi-Vallbona \& Mascarilla-Miro, pg. 37). In a study done by LeRouge, Wiley, \& Maertz (2013), the authors included job security, the work itself, one's supervisor, compensation, work/life balance, and advancement/opportunities as important facets of job satisfaction.

\section{Literature Review}

Age

Previous studies and reports have indicated that age discrimination exists in some information technology fields. Multiple well-known technology-related companies have been accused of age discrimination. An article in Propublica claims that IBM intentionally dismissed approximately 20,000 employees in a fiveyear period over the age of 40 (Gosselin and Tobin, 2018). Google has been in the news multiple times for supposed age discrimination. Before Google's IPO was announced, a 54-year-old employee filed a lawsuit against the company, claiming he was wrongfully terminated due to his age. At that time, employees over the age of 40 comprised less than $2 \%$ of Google's workforce (Hines, 2004). More recently, Google paid $\$ 11$ million to end a class-action lawsuit brought by 227 people that claimed that the company discriminated against job applicants over the age of 40 (Gurchiek, 2019). A 2018 survey of more than 500 tech startup founders indicated that 89 percent of them believed that older workers faced age discrimination in the industry. One-fourth of the respondents thought that age bias begins as early as the age of 36 (Rasheed, 2019). A 2016 report by Statistica indicated that the average median employee age at 17 top tech companies was 32, compared with 42 for the total U.S. workforce. Payscale (2020) reported that the median age is 28 at Facebook, 29 at LinkedIn and SalesForce, 30 at Google, and 33 at Microsoft.

Quan et al (2008) used the human capital model in their research. They found that age discrimination exists in overall IT wages. It does not exist homogeneously in all sectors or in all job functions in the IT workforce, however. Galup, Dattero, and Quan (2004) conducted an empirical validation of age discrimination in computer programmer wages. They discovered that workers more than 40 years old were not equally paid as younger employees after controlling for human capital factors such as education and experience. Bandias and Sharma (2016) found evidence indicating that wages are likely to peak for employees in their mid-50s, with possible decline as they become older. They also reported longer delays for older workers before promotional opportunities become available. Kerr (2019) stated that companies can save money by hiring young H-1B workers rather than older tech workers. Younger men have reported more positive experiences in technology jobs than older men (Corbett, 2019).

\section{Gender and Sexual Preference}

Historically, there have been inequities in compensation based on gender. Women and those that identify as LBTQ have been paid lower salaries for similar jobs. This inequity remains. Dice.com did a study of the gender pay gap in the tech industry (Dice.com, 2020). They found that pay gaps exists between women's and men's salaries even when other factors including job experience, job role, location and education were accounted for. Table 1 show the pay differential for women and men for the different technology occupations. The table shows that on average women software engineers are paid $\$ 8,559$ annually less than men. A study by ChartHop indicates that women in tech make $17.5 \%$ less in wages than men: $\$ 100,895$ vs $\$ 122,234$. The technology field has a lower differential than the overall average job 


\section{Issues in Information Systems}

Volume 22, Issue 4, pp. 249-262, 2021

market. In the US, women earn $20 \%$ less than men on average. The good news is that the gap is declining. In 2018, in the technology field women made on average 23\% less than men (Gruman, 2020). The National Center for Women \& Information Technology (NCWIT) found that new female graduates in computer science average $\$ 79,223$ in pay while males average $\$ 82,159$.

Table 1. Gender Inequities by Occupation (Dice.com, 2020)

\begin{tabular}{|l|c|}
\multicolumn{1}{|c|}{ Occupation } & Differential \\
\hline Mainframe Systems Programmer & $-\$ 16,328^{*}$ \\
\hline DevOps Engineer & $-\$ 15,077^{*}$ \\
\hline Security Architect & $-\$ 14,134^{*}$ \\
\hline Data Architect & $-\$ 13,123$ \\
\hline Database Administrator & $-\$ 11,053$ \\
\hline Data Scientist & $-\$ 9,561$ \\
\hline Data Engineer & $-\$ 9,242$ \\
\hline Software Engineer & $-\$ 8,559$ \\
\hline Security Engineer & $-\$ 6,847$ \\
\hline Technical Recruiter & $-\$ 6,811$ \\
\hline Sales Engineer & $-\$ 6,779^{*}$ \\
\hline Business Analyst & $-\$ 6,455$ \\
\hline Project Manager & $-\$ 5,068$ \\
\hline Product Manager & $-\$ 4,709$ \\
\hline Quality Assurance Engineer & $-\$ 4,404$ \\
\hline Hardware Engineer & $-\$ 2,400^{*}$ \\
\hline Systems Administrator & $-\$ 2,061$ \\
\hline Ul / UX Engineer & $-\$ 1,923$ \\
\hline MIS Manager & $-\$ 1,355$ \\
\hline Web Developer/Programmer & $-\$ 1,180$ \\
\hline Help Desk Support & $-\$ 579$ \\
\hline Cloud Engineer & $+\$ 803^{*}$ \\
\hline Systems Architect & $+\$ 2,446^{*}$ \\
\hline Network Engineer & $+\$ 4,836$ \\
\hline Technical Writer & $+\$ 6,443$ \\
\hline
\end{tabular}

In a 2019 study by hired.com, LGBTQ+ (lesbian, gay, transgender, and queer) men in the tech field are earning on average $4 \%$ less than their non-LGBTQ+ counterparts. LGBTQ+ women in technology are earning $2 \%$ less that non-LGBTQ+ women in the same role. One thing to note on this study: the sample size was small, and this is often hard to measure since many people choose not to self-identify.

Burns (2012) reported that many US gay and transgender workers receive unequal pay. The Williams Institute found that gay and bisexual men earn 10 percent to 32 percent less than heterosexual men. Thomas (2020) indicated that a technology employee's sexual orientation influences salary. Identifying as LGBTQ+ negatively affected salaries for men. However, women who identified as LGBTQ+ made more money than other females in the company. Another study by hired.com (2020) showed that LGBTQ+ women have the biggest gap in wages, earning 90 cents to every dollar that non-LGBTQ+ men earn. 


\section{Issues in Information Systems}

Volume 22, Issue 4, pp. 249-262, 2021

Between 2019 and 2020, the wage gap was flat for all groups except LGBTQ+ women. Their wage gap rose from $\$ 0.92$ in 2019 to $\$ 0.90$ in 2020 .

A study by the Kapor Center for Social Impact (2017) examined why people voluntarily left technologyrelated jobs. Women experienced more unfair treatment overall than men. LGBT employees were most likely to experience public humiliation, embarrassment, and bullying.

\section{Methodology}

To study the compensation and satisfaction of software engineers, we used data from the 2020 Stack Overflow survey with over 65,000 respondents. Stack Overflow's annual Developer Survey is the largest and most comprehensive survey of people who code around the world. Each year, their survey questions cover a wide range of areas, from developers' favorite technologies to their job preferences. According to StackFlow's website:

"For almost a decade, Stack Overflow's annual Developer Survey held the honor of being the largest survey of people who code around the world. This year (2020), rather than aiming to be the biggest, we set out to make our survey more representative of the diversity of programmers worldwide. That said, the survey is still big. This year's survey was taken by nearly 65,000 people." (StackFlow, 2020)

The use of Stack Overflow is well established as a source for peer-reviewed journals including Barua, Thomas, and Hassan (2014), Asaduzzaman, Mashiyat, Roy, and Schneider (2013), and Treude and Robillard (2016). The Stack Overflow dataset consists of dozens of demographics, descriptive, and opinion questions about the state of programming today. The results were analyzed using IBM SPSS 26.

The first step in the analysis was to filter the data set. The data where respondents who identified themselves as hobbyist versus full time developers were removed. Of the 65,000 respondents, 47,200 self-identified as developers by profession. Since this is an international survey, we then further filtered it down to 7,304 who were self-identified as based in the US. We used this subset to examine equity and satisfaction in the United States. As a result, our work is limited to a study of equity and satisfaction of Information Technology developers in the United States only and all conclusions apply only to US workers.

For our dependent variables we used compensation as self-reported in annual US dollars and overall job satisfaction as measured in the survey. The specific question was, "How satisfied are you with your current job? (If you work multiple jobs, answer for the one you spend the most hours on.)" The options were very dissatisfied, slightly dissatisfied, neither satisfied nor dissatisfied, slightly satisfied, and very satisfied.

\section{Results}

The overall results of our statistical analysis are presented in the following subsections. Overall, we examined both the compensation and job satisfaction dependent variables and any significant differences based on gender, ethnicity(race), sexual preference, and age. Since many of these variables were categorical and had many options, in some cases we deleted low volume categories and in others we performed post hoc analyses to determine where specific differences and inequities were present. 


\section{Issues in Information Systems}

Volume 22, Issue 4, pp. 249-262, 2021

\section{Gender}

Analysis of US compensation by gender revealed a large and significant gap by gender as shown in Table 2 . The difference was nearly $\$ 16,000$ per year between men and women in the survey. Other genders including non-binary and non-conforming did not see these significant differences although their $\mathrm{N}$ is very low and precluded any definitive conclusions. The gender pay gap still exists and was statistically significant at $p<.000$. This suggests that a gender inequity remains. A possible source for the inequity may have been differences in education level. To address this, we also analyzed gender by education level. The results are given in Tables 3 and 4. We found that across all educational levels, there remained a large gap between men and women. Also, both variables were significant at $\mathrm{p}<.001$ in multiple regression analysis. However, when we examined job satisfaction based on gender, we did not see a significant gender gap (Table 5). Overall, the results show no significant difference in job satisfaction based on gender at $\mathrm{p}<.504$. So even though there is a gender inequity based on compensation, perceived job satisfaction had not been affected.

Table 2. Compensation Total by Gender

\begin{tabular}{|lc|c|c|}
\hline Gender & Mean & $\mathbf{N}$ & Std. Dev. \\
\hline Man & $\$ 122,514$ & 6,003 & $\$ 71,488$ \\
\hline Man;Non-binary, genderqueer, or gender non-conforming & 103,560 & 28 & 47,983 \\
\hline NA & 126,106 & 490 & 81,639 \\
\hline Non-binary, genderqueer, or gender non-conforming & 119,757 & 87 & 85,080 \\
\hline Woman & 106,538 & 669 & 59,576 \\
\hline Woman;Man & 74,833 & 3 & 15,671 \\
\hline Woman;Man;Non-binary, genderqueer, or gender non-conforming & 154,375 & 2 & 6,187 \\
\hline Woman;Non-binary, genderqueer, or gender non-conforming & 118,054 & 22 & 73,178 \\
\hline Overall & $\mathbf{\$ 1 2 1 , 1 6 2}$ & $\mathbf{7 , 3 0 4}$ & $\mathbf{\$ 7 1 , 4 5 3}$ \\
\hline
\end{tabular}

Table 3. Salary Based on Education Level and Gender

\begin{tabular}{|l|r|r|r|r|r|}
\hline \multicolumn{1}{|c|}{$\begin{array}{c}\text { Educational } \\
\text { Level }\end{array}$} & \multicolumn{1}{|c|}{ Mean } & \multicolumn{1}{c|}{ N } & \multicolumn{1}{c|}{ Mean } & \multicolumn{1}{c|}{ N } & \multicolumn{1}{c|}{$\begin{array}{c}\text { Men Vs Women } \\
\text { Differential }\end{array}$} \\
\hline No formal & $\$ 93,531$ & 53 & $\$ 92,211$ & 9 & $\$ 1,320$ \\
\hline Primary & 101,906 & 17 & 34,000 & 2 & 67,906 \\
\hline Secondary & 95,763 & 131 & 72,225 & 13 & 23,538 \\
\hline Some College & 121,605 & 724 & 91,289 & 41 & 30,316 \\
\hline Associate & 91,798 & 306 & 77,274 & 28 & 14,524 \\
\hline Bachelor's & 119,931 & 3,551 & 105,865 & 421 & 14,066 \\
\hline Masters & 138,365 & 1,048 & 118,101 & 131 & 20,264 \\
\hline Doctoral & 168,823 & 173 & 145,446 & 24 & 23,377 \\
\hline Overall & $\mathbf{\$ 1 2 2 , 5 1 5}$ & $\mathbf{6 , 0 0 3}$ & $\mathbf{\$ 1 0 6 , 5 3 9}$ & $\mathbf{6 6 9}$ & $\mathbf{\$ 1 5 , 9 7 6}$ \\
\hline
\end{tabular}


Table 4 Salary with Gender and Educational Level

\begin{tabular}{|l|rr|r|rr|}
\hline & \multicolumn{2}{|c|}{ Unstandardized Coefficients } & Std. Coeffs & & \\
Model & \multicolumn{1}{|c|}{$\mathrm{B}$} & Std. Error & Beta & \multicolumn{1}{c|}{$\mathrm{S}$} \\
\hline (Constant) & 79697.264 & 4477.583 & & 17.799 & .000 \\
Gender & -3137.018 & 637.019 & -.057 & -4.925 & .000 \\
Education Level & 7948.135 & 740.399 & .125 & 10.735 & .000 \\
\hline
\end{tabular}

a. Dependent Variable: Compensation Total

Table 5. Job Satisfaction by Gender

\begin{tabular}{|lc|c|c|}
\hline Gender & Mean & N & Std. Dev. \\
\hline Man & 3.81 & 4,196 & 1.50 \\
\hline Man;Non-binary, genderqueer, or gender non-conforming & 4.47 & 15 & 1.12 \\
\hline NA & 3.73 & 346 & 1.53 \\
\hline Non-binary, genderqueer, or gender non-conforming & 3.90 & 69 & 1.41 \\
\hline Woman & 3.90 & 480 & 1.49 \\
\hline Woman;Man & 3.50 & 2 & 2.12 \\
\hline Woman;Man;Non-binary, genderqueer, or gender non-conforming & 3.00 & 1 & - \\
\hline Woman;Non-binary, genderqueer, or gender non-conforming & 3.94 & 16 & 1.482 \\
\hline Overall & $\mathbf{3 . 8 1}$ & $\mathbf{5 , 1 2 5}$ & $\mathbf{1 . 5 0 2}$ \\
\hline
\end{tabular}

\section{Ethnicity/Race}

When we examined compensation by ethnicity/race we did not find significant differences $(\mathrm{p}<.468)$. The results of all ethnicity categories with more than 50 respondents are shown in Table 6 . The $\mathrm{p}$ value is calculated based on all 209 different ethnicity categories identified. But this overall difference seemed to be disguising some paired comparisons. As a result, a Bonferroni Post hoc analysis was performed on the dataset. Significant differences were found when this was performed. Specifically, East Asian was significantly higher than Hispanic or Latino/a/x with $\mathrm{p}<.022$. White or of European descent was significantly higher than Hispanic or Latino/a/x at $\mathrm{p}<.006$. South Asian was also significantly higher than Hispanic or Latino/a/x at $\mathrm{p}<.001$. We therefore found limited ethnicity inequity based on compensation. Hispanic IT developers seem to be negatively affected by ethnicity inequity. A possible source for the inequity may have been differences in education level. To address this, we also analyzed ethnicity by education level in Tables 7 and 8 . We found that across all educational levels (with one low count anomaly), there remained a large gap between East Asian and Hispanic, white and Hispanic, and South Asian and Hispanic. To further illustrate this large gap a table with the compensation differential with Hispanics is shown in Table 9. For example, South Asians with a bachelor's degree make on average $\$ 26,998$ more than Hispanics with a bachelor's degree. Similarly, whites with a bachelor's degree make $\$ 30,955$ more than Hispanics.

When job satisfaction was used as the dependent variable, these individual Bonferroni post hoc differences disappeared. The overall results are significantly different at $\mathrm{p}<.001$, but individual paired differences are not significant. Again, it appears that this inequity is accepted and does not impact job satisfaction. 


\section{Issues in Information Systems}

Volume 22, Issue 4, pp. 249-262, 2021

Table 6. Compensation Total by Ethnicity

\begin{tabular}{|c|c|c|c|}
\hline Ethnicity & Mean & $\mathbf{N}$ & Std. Dev. \\
\hline Black or of African descent & $\$ 109,636$ & 102 & $\$ 53,987$ \\
\hline East Asian & 127,924 & 170 & 80,580 \\
\hline Hispanic or Latino/a/x & 103,811 & 208 & 50,281 \\
\hline Hispanic or Latino/a/x; White or of European descent & 118,716 & 114 & 62,986 \\
\hline Middle Eastern & 118,455 & 54 & 69,358 \\
\hline South Asian & 133,663 & 197 & 69,608 \\
\hline Southeast Asian & 116,449 & 90 & 58,011 \\
\hline White or of European descent & 122,007 & 5,285 & 72,049 \\
\hline Overall & $\$ 121,162$ & 7,304 & $\$ 71,453$ \\
\hline
\end{tabular}

Table 7. Compensation by Educational Level and Ethnicity

\begin{tabular}{|l|c|c|c|c|c|c|c|c|}
\hline \multirow{2}{*}{$\begin{array}{c}\text { Educational } \\
\text { Level }\end{array}$} & \multicolumn{2}{|c|}{ South Asian } & \multicolumn{2}{c|}{ East Asian } & \multicolumn{2}{c|}{$\begin{array}{c}\text { Hispanic/ } \\
\text { Latinx }\end{array}$} & \multicolumn{2}{c|}{ White } \\
& Mean & $\mathbf{N}$ & Mean & N & Mean & N & Mean & N \\
\hline No formal & - & - & - & - & $\$ 103,214$ & 7 & $\$ 99,729$ & 44 \\
\hline Primary & - & - & - & - & - & - & 97,067 & 18 \\
\hline Secondary & - & - & $\$ 63,500$ & 2 & 81,105 & 7 & 94,597 & 108 \\
\hline Some College & $\begin{array}{c}\$ 106,66 \\
7\end{array}$ & 3 & 126,165 & 8 & 94,979 & 20 & 122,548 & 639 \\
\hline Associate & - & - & - & - & 91,782 & 10 & 91,813 & 283 \\
\hline Bachelor's & 132,420 & 83 & 125,802 & 112 & 105,422 & 131 & 118,622 & 3,18 \\
\hline Masters & 133,103 & 105 & 126,157 & 44 & 110,802 & 31 & 141,757 & 850 \\
\hline Doctoral & 174,167 & 6 & 242,500 & 4 & 120,000 & 2 & 163,382 & 159 \\
\hline Overall & $\begin{array}{c}\mathbf{\$ 1 3 3 , 6 6} \\
\mathbf{3}\end{array}$ & $\mathbf{1 9 7}$ & $\mathbf{\$ 1 2 7 , 9 2 4}$ & $\mathbf{1 7 0}$ & $\mathbf{\$ 1 0 3 , 8 1 2}$ & $\mathbf{2 0 8}$ & $\begin{array}{c}\mathbf{\$ 1 2 2 , 0 0} \\
\mathbf{7}\end{array}$ & $\mathbf{5 , 2 8}$ \\
\hline
\end{tabular}


Table 8. Compensation based on Education and Ethnicity

\begin{tabular}{|l|c|c|c|c|c|c|c|c|}
\hline & \multicolumn{2}{|c|}{\begin{tabular}{c} 
South Asian \\
\multicolumn{1}{|c|}{ Lducational } \\
Level
\end{tabular}} & \multicolumn{2}{c|}{ East Asian } & \multicolumn{2}{c|}{$\begin{array}{c}\text { Hispanic/ } \\
\text { Latinx }\end{array}$} & \multicolumn{2}{c|}{ White } \\
\hline No formal & - & - & - & - & $\$ 103,214$ & 7 & $\$ 99,729$ & 44 \\
\hline Primary & - & - & - & - & - & - & 97,067 & 18 \\
\hline Secondary & - & - & $\$ 63,500$ & 2 & 81,105 & 7 & 94,597 & 108 \\
\hline Some College & $\begin{array}{c}\$ 106,66 \\
7\end{array}$ & 3 & 126,165 & 8 & 94,979 & 20 & 122,548 & 639 \\
\hline Associate & - & - & - & - & 91,782 & 10 & 91,813 & 283 \\
\hline Bachelor's & 132,420 & 83 & 125,802 & 112 & 105,422 & 131 & 118,622 & 3,18 \\
\hline Masters & 133,103 & 105 & 126,157 & 44 & 110,802 & 31 & 141,757 & 850 \\
\hline Doctoral & 174,167 & 6 & 242,500 & 4 & 120,000 & 2 & 163,382 & 159 \\
\hline Overall & $\mathbf{\$ 1 3 3 , 6 6}$ & $\mathbf{1 9 7}$ & $\mathbf{\$ 1 2 7 , 9 2 4}$ & $\mathbf{1 7 0}$ & $\mathbf{\$ 1 0 3 , 8 1 2}$ & $\mathbf{2 0 8}$ & $\mathbf{\$ 1 2 2 , 0 0}$ & $\mathbf{5 , 2 8}$ \\
\hline
\end{tabular}

Table 9. Compensation Differential between Hispanics and other Ethnicities

\begin{tabular}{|l|c|c|c|}
\hline $\begin{array}{c}\text { Educational } \\
\text { Level }\end{array}$ & S. Asian & E. Asian & White \\
\hline No formal & - & - & $-\$ 3,485$ \\
\hline Primary & - & - & - \\
\hline Secondary & - & $-\$ 17,605$ & 13,492 \\
\hline Some College & $-\$ 11,688$ & 31,186 & 27,569 \\
\hline Associate & - & - & -31 \\
\hline Bachelor's & 26,998 & 20,380 & 13,200 \\
\hline Masters & 22,301 & 15,355 & 30,955 \\
\hline Doctoral & 54,167 & 122,500 & 43,382 \\
\hline Overall & $\mathbf{\$ 2 9 , 8 5 1}$ & $\mathbf{\$ 2 4 , 1 1 2}$ & $\mathbf{\$ 1 8 , 1 9 6}$ \\
\hline
\end{tabular}

Table 10. Job Satisfaction by Ethnicity

\begin{tabular}{|lc|c|c|}
\hline Ethnicity & Mean & N & Std. Dev. \\
\hline Black or of African descent & 4.08 & 72 & 1.48 \\
\hline East Asian & 3.51 & 119 & 1.47 \\
\hline Hispanic or Latino/a/x & 3.66 & 151 & 1.52 \\
\hline Hispanic or Latino/a/x;White or of European descent & 4.01 & 82 & 1.46 \\
\hline Middle Eastern & 3.21 & 38 & 1.647 \\
\hline South Asian & 3.58 & 147 & 1.54 \\
\hline White or of European descent & 3.86 & 3,693 & 1.49 \\
\hline Overall & $\mathbf{3 . 8 4}$ & $\mathbf{4 , 3 0 2}$ & $\mathbf{1 . 5 0}$ \\
\hline
\end{tabular}




\section{Issues in Information Systems}

Volume 22, Issue 4, pp. 249-262, 2021

\section{Sexuality}

Sexuality or sexual preference does not seem to have a significant impact on compensation (Table 11). The $\mathrm{p}$ value is close at .051 and there does seem to be reduced compensation for bisexual individuals versus gay or straight but we cannot conclude that there is statistically significant inequity in IT based on sexuality. Even that difference seems to disappear when job satisfaction is measured. Overall, $\mathrm{p}<.359$ (Table 12).

Table 11. Compensation by Sexuality

\begin{tabular}{|lc|c|c|}
\hline Sexuality & Mean & N & $\begin{array}{c}\text { Std. } \\
\text { Dev. }\end{array}$ \\
\hline Bisexual & $\$ 112,334$ & 283 & $\$ 73,836$ \\
\hline Bisexual;Gay or Lesbian & 102,837 & 3 & 27,908 \\
\hline Bisexual;Gay or Lesbian;Queer & 146,276 & 7 & 83,231 \\
\hline Bisexual;Gay or Lesbian;Straight / Heterosexual & - & 1 & - \\
\hline Bisexual;Gay or Lesbian;Straight / Heterosexual; Queer & 91,000 & 1 & - \\
\hline Bisexual;Queer & 109,507 & 60 & 61,900 \\
\hline Bisexual;Straight / Heterosexual & 112,837 & 34 & 54,176 \\
\hline Bisexual;Straight / Heterosexual;Queer & 132,000 & 1 & - \\
\hline Gay or Lesbian & 121,017 & 163 & 69,374 \\
\hline Gay or Lesbian;Queer & 108,301 & 29 & 59,845 \\
\hline Gay or Lesbian;Straight / Heterosexual & 66,698 & 2 & 4,669 \\
\hline NA & 132,034 & 331 & 89,676 \\
\hline Queer & 107,063 & 63 & 67,875 \\
\hline Straight / Heterosexual & 121,998 & 5,141 & 70,096 \\
\hline Straight / Heterosexual;Queer & 108,863 & 11 & 42,708 \\
\hline Overall & $\mathbf{\$ 1 2 1 , 6 3 0}$ & $\mathbf{6 , 1 3 0}$ & $\mathbf{\$ 7 1 2 5 2}$ \\
\hline
\end{tabular}

Table 12. Job Satisfaction by Sexuality

\begin{tabular}{|lc|c|c|}
\hline Sexuality & Mean & N & Std. Dev. \\
\hline Bisexual & 3.93 & 208 & 1.43 \\
\hline Bisexual;Gay or Lesbian & 5.00 & 2 & .00 \\
\hline Bisexual;Gay or Lesbian;Queer & 4.20 & 5 & 1.78 \\
\hline Bisexual;Gay or Lesbian;Straight / Heterosexual & 5.00 & 1 & - \\
\hline Bisexual;Gay or Lesbian;Straight / Heterosexual; Queer & 2.00 & 1 & - \\
\hline Bisexual;Queer & 4.37 & 41 & 1.15 \\
\hline Bisexual;Straight / Heterosexual & 3.57 & 21 & 1.32 \\
\hline Gay or Lesbian & 3.90 & 118 & 1.45 \\
\hline Gay or Lesbian;Queer & 4.00 & 18 & 1.45 \\
\hline Gay or Lesbian;Straight / Heterosexual & 5.00 & 1 & - \\
\hline NA & 3.77 & 245 & 1.51 \\
\hline Queer & 3.51 & 49 & 1.62 \\
\hline Straight / Heterosexual & 3.83 & 3,585 & 1.50 \\
\hline Straight / Heterosexual;Queer & 3.57 & 7 & 1.81 \\
\hline Overall & $\mathbf{3 . 8 4}$ & $\mathbf{4 , 3 0 2}$ & $\mathbf{1 . 4 9}$ \\
\hline
\end{tabular}




\section{Issues in Information Systems}

Volume 22, Issue 4, pp. 249-262, 2021

\section{Age}

Finally, we examined age as an independent variable affecting both compensation and job satisfaction (Tables 13 and 14). Many researchers have suggested an age bias against older workers. About compensation, we found no such bias. In fact, age correlates positively with compensation. The older you are, the higher your compensation. Bias may be a factor for obtaining employment, but this is not reflected in compensation paid. But we also found that as age increases, job satisfaction decreases. It is unclear what is the cause of this factor. Burnout or just multiple years in the same profession may have an effect here. Further research is needed to determine the cause of this negative correlation. This correlation is significant at $\mathrm{p}<.021$.

Table 13. Regression analysis of age and compensation

\begin{tabular}{|llrrrrr|}
\hline Model & & \multicolumn{1}{c}{ B } & Std. Error & Beta & \multicolumn{1}{c|}{ t } & \multicolumn{1}{c|}{ Sig. } \\
\hline 1 & (Constant) & 62485.871 & 3061.121 & & 20.413 & .000 \\
& Age & 1694.939 & 86.301 & .237 & 19.640 & .000 \\
\hline
\end{tabular}

a. Dependent Variable: Compensation Total

Table 14. Regression analysis of age and job satisfaction

\begin{tabular}{|llccccc|}
\hline Model & & B & Std. Error & Beta & t & Sig. \\
\hline 1 & (Constant) & 3.999 & .080 & & 49.759 & .000 \\
& Age & -.005 & .002 & -.034 & -2.310 & .021 \\
\hline
\end{tabular}

a. Dependent Variable: Job Satisfaction Normalized

\section{Discussion and Conclusions}

Overall, our study suggests that inequity seems continues to exist in the software engineering, a major portion of the Information Technology job market. Gender has a significant impact on compensation with females earning about $\$ 16,000$ less than other genders. Likewise, ethnicity has a significant impact for Hispanic workers. No inequities were seen with other ethnicities however, including Asian and Black ethnicities. For both ethnicity and gender, however, neither of these inequities seemed to carry over into job satisfaction. It appears that these inequities are an accepted practice and do not affected the specific biased groups perceptions of their work. For other demographic categories, namely age and sexual preference, our analyses found no inequities in either compensation or job satisfaction.

Our work extends the literature on inequity in employment based on demographic groups. However, it is limited using only the two measures of compensation and job satisfaction. Other inequities may exist such as initial employment and promotional levels. Further work is needed to review these and other potential inequities. In addition, our work is limited by self-reporting as well as active members of the StackOverflow community. Though this is a robust dataset, data may be skewed by those who choose to be a member of StackOverflow and those who participated in the survey.

\section{References}

Asaduzzaman, M., Mashiyat, A. S., Roy, C. K., \& Schneider, K. A. (2013, May). Answering questions about unanswered questions of stack overflow. In 2013 10th Working Conference on Mining Software Repositories (MSR) (pp. 97-100).

Bandias, S. \& Sharma, R. (2016). The Workplace Implications of Ageism for Women in the Australian ICT Sector. International Journal of Business, Humanities and Technology, 6(4), 7-17. 


\section{Issues in Information Systems}

Volume 22, Issue 4, pp. 249-262, 2021

Barua, A., Thomas, S. W., \& Hassan, A. E. (2014). What are developers talking about? an analysis of topics and trends in stack overflow. Empirical Software Engineering, 19(3), 619-654.

Bostock v. Clayton County, No. 17-1618, 590 U.S. (2020).

Crespi-Vallbona, M., \& Mascarilla-Miro, O. (2018, 2nd Quarter). Job Satisfaction: The Case of Information Technology (IT) Professionals in Spain. Universia Business Review(58), 36-51. doi:10.3232/UBR.2018.V15.N2.02

Dice.com (2020) The Gender Pay Gap in Tech for Technologists. retrieved on June 6, 2021 from http://marketing.dice.com/pdf/2020/Dice_Gender_Pay_Gap_In_Tech_Report Technologists.pdf?utm source=ebook\&utm medium=email\&utm_campaign=gender_pay_gap 2020 softregistrationcandi date report

Gosslin, P. \& Tobin, A. (2019). Cutting 'Old Heads' at IBM. https://features.propublica.org/ibm/ibm-agediscrimination-american-workers/

Gurchiek, K. (2019). Google Ends Age-Discrimination Suit with \$11 Million Settlement. https://www.shrm.org/resourcesandtools/hr-topics/behavioral-competencies/global-and-culturaleffectiveness/pages/google-ends-age-discrimination-suit-with-11-million-settlement.aspx.

Gruman, G. (2020) Women do better, minorities worse, when it comes to the tech wage gap. ComputerWorld, Oct 21, retrieved on June 6, 2021, from https://www.computerworld.com/article/3586552/women-do-better-minorities-worse-when-itcomes-to-the-tech-wagegap.html\#: :text=The $\% 20$ ChartHop $\% 20$ customer $\% 20$ data $\% 20$ shows,less $\% 20$ than $\% 20$ men $\% 2 \mathrm{C}$ $\% 20$ on $\% 20$ average.

Hired.com (2019) The State of Wage Inequality in the Workplace.

Jordan, C. E., Clark, S. J., \& Waldron, M. A. (2007). Gender bias and compensation in the executive suite of the Fortune 100. Journal of Organizational Culture, Communications and Conflict, 11(1), 19.

Payscale(2020) https://www.payscale.com/data-packages/top-tech-companies-compared/tech-salaries

Kerr, W. R. (2019). The plight of the graying tech worker. MIT Sloan Management Review, 60(3), 1-4.

LeRouge, C. M., Wiley, J. W., \& Maertz, J. C. (2013). A Comparison of Job Satisfaction between IT and Non-IT Women Incumbents in Clerical, Professional, and Managerial Positions. The DATA BASE for Advances in Information Systems, 44(2), 39-54.

Lumley, E., Coetzee, M., Tladinyane, R., \& Ferreira, N. (2011). Exploring the job satisfaction and organizational commitment of employees in the information technology environment. Southern African Business Review, 15(1).

Pook, L. A., Füstös, J., \& Marian, L. (2003). The impact of gender bias on job satisfaction. Human Systems Management, 22(1), 37-50. 


\section{Issues in Information Systems}

Volume 22, Issue 4, pp. 249-262, 2021

Quan, J., Dattero, R., \& Galup, S. D. (2008). An explorative study of age discrimination in IT wages. Information Resources Management Journal, 21(3), 24-38.

Rasheed, Mahreen (2019). Tech Companies Settle Age Bias Suits. https://www.lexology.com/library/detail.aspx?g=5c732053-42b4-4f79-b29a-ef3dd8f416b0.

Scott, A., Klein, F., \& Onovakpuri, U. (2017). Tech Leavers Study. https://mk0kaporcenter5ld71a.kinstacdn.com/wp-content/uploads/2017/08/TechLeavers2017.pdf.

Sempane, M., Rieger, H., \& Roodt, G. (2002). Job Satisfaction in Relation to Organisational Culture. SA Journal of Industrial Psychology, 28(2), 23-30.

Stack Overflow https://insights.stackoverflow.com/survey/2020\#overview

Thomas, R. (2020). The 2020 State of Pay Equity In The Tech Industry. https://blog.curocomp.com/stateof-pay-equity-in-tech-industry-2020.

Treude, C., \& Robillard, M. P. (2016, May). Augmenting api documentation with insights from stack overflow. In 2016 IEEE/ACM 38th International Conference on Software Engineering (ICSE) (pp. 392-403).

\section{Appendix 1. Key Survey questions}

Which of the following options best describes you today? Here, by "developer" we mean "someone who writes code." *

- I am a developer by profession.

- I am not primarily a developer, but I write code sometimes as part of my work.

- I used to be a developer by profession, but no longer am.

- I am a student who is learning to code.

- I code primarily as a hobby.

- None of these.

Which of the following best describes the highest level of formal education that you've completed?

- I never completed any formal education

- Primary/elementary school

- Secondary school (e.g. American high school, German Realschule or Gymnasium, etc.)

- Some college/university study without earning a degree

- Associate degree (A.A., A.S., etc.)

- Bachelor's degree (B.A., B.S., B.Eng., etc.)

- Master's degree (M.A., M.S., M.Eng., MBA, etc.)

- Professional degree (JD, MD, etc.)

- Other doctoral degree (Ph.D., Ed.D., etc.)

- Other (please specify 


\section{Issues in Information Systems}

Volume 22, Issue 4, pp. 249-262, 2021

What is your current total compensation (salary, bonuses, and perks, before taxes and deductions), in \$. Please enter a whole number in the box below, without any punctuation. If you are paid hourly, please estimate an equivalent weekly, monthly, or yearly salary. If you prefer not to answer, please leave the box empty.

How satisfied are you with your current job? (If you work multiple jobs, answer for the one you spend the most hours on.)

- Very dissatisfied

- Slightly dissatisfied

- Neither satisfied nor dissatisfied

- Slightly satisfied

- Very satisfied 